\title{
Influence of Four Retail Food Service Cooling Methods on the Behavior of Clostridium perfringens ATCC 10388 in Turkey Roasts following Heating to an Internal Temperature of $74^{\circ} \mathrm{C}$
}

\author{
D. A. OLDS, ${ }^{1}$ A. F. MENDONCA,${ }^{2 *}$ J. SNEED, ${ }^{1}$ AND B. BISHA ${ }^{2}$
}

${ }^{1}$ Foodservice and Lodging Management Program, 31 MacKay Hall, and ${ }^{2}$ Department of Food Science and Human Nutrition, 2312 Food Sciences Building, Iowa State University, Ames, Iowa 50011, USA

MS 05-27: Received 31 January 2005/Accepted 29 April 2005

\begin{abstract}
The influence of four food service cooling methods (CM) on growth of Clostridium perfringens ATCC 10388 in cooked turkey roasts was evaluated. Raw whole turkey roasts were inoculated with $C$. perfringens spores $(\sim 4.23$ log CFU per roast), vacuum packaged, and heated to an internal temperature of $74^{\circ} \mathrm{C}$. The cooked roasts were cooled as follows: whole roast cut into four quarters and held at $4^{\circ} \mathrm{C}(\mathrm{CM} 1)$; whole roast held in a blast chiller (CM2); whole roast loosely wrapped and held at $4^{\circ} \mathrm{C}$ (CM3); and whole roasts (three per bag) held at $4^{\circ} \mathrm{C}(\mathrm{CM} 4)$. The roasts were analyzed for $C$. perfringens using ShahidiFerguson perfringens agar and anaerobic incubation $\left(37^{\circ} \mathrm{C}, 24 \mathrm{~h}\right)$. None of the cooling methods met the amended 2001 U.S. Food and Drug Administration Food Code guidelines for safe cooling of potentially hazardous foods. Times taken for roasts to cool from 57 to $21^{\circ} \mathrm{C}$ using CM1, CM2, CM3, and CM4 were 2.27, 3.11, 6.22, and 8.71 h, respectively. Times taken for roasts $\left(21^{\circ} \mathrm{C}\right)$ to reach $5^{\circ} \mathrm{C}$ ranged from 6.33 (CM1) to $19.45 \mathrm{~h}$ (CM4). Based on initial numbers of $C$. perfringens, no growth occurred in roasts cooled by CM1 or CM2, whereas numbers increased by 1.5 and 4.0 log in whole roasts cooled via CM3 and CM4, respectively. These findings indicate that certain food service cooling methods for whole cooked turkey roasts may result in proliferation of $C$. perfringens and increase the risk of foodborne illness by this pathogen.
\end{abstract}

Clostridium perfringens is a gram-positive, anaerobic spore-forming pathogenic bacterium whose spores are common contaminants of a variety of foods (12). This pathogen is an ongoing concern in retail food service where large volumes of food are prepared in advance and cooled before reheating for service (27). Improper cooling of food was identified as the number one factor that contributed to the occurrence of 1,918 outbreaks of $C$. perfringens food poisoning in the United States from 1961 to 1982 (2). From 1983 to 1992 there were an estimated 654 reported outbreaks of $C$. perfringens food poisoning resulting in 248,520 cases (14). Based on surveillance information in the United States from 1993 to 1997, C. perfringens is responsible for $8.7 \%$ of all reported outbreaks (3). C. perfringens has been linked to foodborne illness involving roast beef, turkey, meat-containing Mexican foods, and other meat dishes (2).

Cooking meat products in retail food service is normally sufficient to destroy $C$. perfringens vegetative cells but not the spores of this pathogen. For example, cooking beef roasts $(1.45 \mathrm{~kg}$ each) to an internal temperature of $60^{\circ} \mathrm{C}$ for $2.3 \mathrm{~h}$ or longer can result in a $12-\log$ reduction of C. perfringens vegetative cells (18). However, spores of this pathogen typically survive the cooking process and are heat shocked, triggering them to germinate during improper cooling. While heating at 70 to $80^{\circ} \mathrm{C}$ for about $20 \mathrm{~min}$ is required to heat shock $C$. perfringens spores to induce ger-

* Author for correspondence. Tel: 515-294-2950; Fax: 515-294-8181;

E-mail: amendon@iastate.edu. mination $(8,12)$, the use of lower temperatures (e.g., 55 to $60^{\circ} \mathrm{C}$ ) in low-temperature, long-time cooking of meats can also serve to activate spores (1). Improper cooling allows outgrowth of $C$. perfringens vegetative cells, which can multiply rapidly to reach high numbers within slow-cooling bulk products such as turkey roasts. As cooked meat dishes cool they will inevitably traverse the growth temperature range $\left(50\right.$ to $15^{\circ} \mathrm{C}$ ) for $C$. perfringens (12). Therefore, rapid cooling of cooked foods is crucial to prevent proliferation of this pathogen, whose population can double every 7.1 min between 41 and $46^{\circ} \mathrm{C}$ (13).

According to the U.S. Department of Agriculture (USDA) Food Safety and Inspection Service guidelines for cooling of meat products, the internal temperature of cooked meats should not remain between 54.4 and $26.7^{\circ} \mathrm{C}$ for over $1.5 \mathrm{~h}$ nor between 26.7 and $4.4^{\circ} \mathrm{C}$ for more than $5 \mathrm{~h}$ during cooling (24). If meat processors are unable or not willing to meet these cooling guidelines, they must prove that an alternative cooling regimen will give less than 1-log increase in growth of $C$. perfringens and no growth of Clostridium botulinum (24). According to the performance standards for the cooling of ready-to-eat meat products that were published in the Federal Register 66(39) in February 2001, there should not be more than 1.0-log multiplication of $C$. perfringens within these products during cooling (26). In 2003, the U.S. Food and Drug Administration (FDA) amended their 2001 Food Code $(28,29)$ and recommended that all potentially hazardous foods be cooled from 57 to $21^{\circ} \mathrm{C}$ in $2 \mathrm{~h}$ and then from 21 to $5^{\circ} \mathrm{C}$ in an additional $4 \mathrm{~h}$ (29). Based on observational studies, retail 
food service procedures might not be meeting these FDA cooling recommendations. Henroid and Sneed (5) found that in most school food service operations employees were not measuring food temperatures. In operations where food temperatures were measured, often the data were not documented, employees did not calibrate thermometers, and documentation of calibration was nonexistent in all schools studied. Also, six of ten school food service operations were not in compliance with FDA recommendations for cooling potentially hazardous foods (5). Snyder and Labalestra (20) found that health departments were not conducting cooling studies to verify the FDA-recommended 6$\mathrm{h}$ cooling time in retail food service and that this standard was a very difficult one to meet using typical food service refrigeration facilities.

The gap between FDA cooling recommendations and verification of cooling standards, coupled with observations of noncompliance of retail food service cooling procedures, served as impetus for this study. To our knowledge there is no published research on cooling time, product temperature, and growth of $C$. perfringens as affected by four different food service cooling methods employed for USDA commodity turkey roasts $(5.1 \mathrm{~kg}$ each). Accordingly, the objectives of this research were to (i) develop time and temperature cooling curves for USDA commodity turkey roasts using selected food service cooling methods, and (ii) evaluate the influence of these cooling methods on the behavior of $C$. perfringens ATCC 10388 in turkey roasts following heating to an internal temperature of $74^{\circ} \mathrm{C}$.

\section{MATERIALS AND METHODS}

Bacterial strain and spore suspension. C. perfringens strain ATCC 10388, isolated from lamb that developed enterotoxemia, was obtained from the American Type Culture Collection. C. perfringens spores were maintained in cooked meat medium (Difco, Becton Dickinson, Sparks, Md.) at $4^{\circ} \mathrm{C}$ and used as stock culture throughout the present study. The organism was cultured in fluid thioglycollate medium and sporulation was induced in modified Duncan-Strong sporulation medium (4) as described by Juneja et al. (9). The spore crop was harvested by centrifugation $(10,000$ $\left.\times g, 10 \mathrm{~min}, 4^{\circ} \mathrm{C}\right)$, resuspended in physiological saline $(0.85 \%$ $\mathrm{wt} / \mathrm{vol}$ sodium chloride), then diluted in fresh saline to give a final spore concentration of approximately $1.7 \times 10^{4} \mathrm{CFU} / \mathrm{ml}$. The diluted spore suspension was combined with filter-sterilized green food coloring (four drops of coloring per $10 \mathrm{ml}$ of spore suspension) immediately before injection into turkey roasts.

Sample preparation and inoculation. Raw boneless turkey roasts $(5.1 \mathrm{~kg}$ each) measuring $39.8 \mathrm{~cm}$ (length) and $13.9 \mathrm{~cm}$ (diameter), and packaged in a heat-sealed plastic film, were obtained from the USDA's Food and Nutrition Service. The roasts were kept frozen $\left(-17.7^{\circ} \mathrm{C}\right)$ for no more than 2 months before use. Prior to each experiment, roasts were placed in a walk-in refrigerator at $4^{\circ} \mathrm{C}$ for $48 \mathrm{~h}$ until they were completely thawed. All roasts were inoculated using the same procedure, with a slight modification for roasts that were to be cut into quarters after heating. Thawed turkey roasts were inoculated with $C$. perfringens spores to give a final spore concentration of approximately 4.23 $\log$ CFU per roast. Inoculation was performed via use of a 15.2cm 20-gauge needle (Fisher Scientific Co., Pittsburgh, Pa.) to inject $1.0 \mathrm{ml}$ of the green-colored spore suspension in the geometric center of each roast. The geometric center $(6.98 \mathrm{~cm})$ of each roast
TABLE 1. Treatment code for and description of each retail food service cooling method (CM) used for turkey roasts

\begin{tabular}{cl}
\hline $\begin{array}{c}\text { Treatment } \\
\text { code }\end{array}$ & \multicolumn{1}{c}{ Description of cooling method } \\
\hline CM1 & Roast quartered, uncovered, in walk-in refrigerator \\
CM2 & Whole roast loosely wrapped, in blast chiller \\
CM3 & Whole roast loosely wrapped, in walk-in refrigerator \\
CM4 & $\begin{array}{c}\text { Whole roasts (three per bag) on sheet pans, in walk- } \\
\text { in refrigerator }\end{array}$ \\
& \\
\hline
\end{tabular}

was determined by measuring the circumference $(C)$ of the respective roasts and applying the mathematical formula $C=\pi D$. This formula was used to obtain the radius $(0.5 D)$, which represented the center of the roast in which the spore suspension was injected. Roasts that were to be cut into quarters after heating were marked (using a permanent marker) into four 9.9-cm-thick sections. The roasts were inoculated with $1.0 \mathrm{ml}$ of the spore suspension in the center of one of the two inner sections.

A thermocouple type-K probe (Fisher Scientific Co.) was inserted next to the inoculum at the same depth $(6.98 \mathrm{~cm})$, in the center of each turkey roast. For roasts that were to be cut into quarters, a type-K probe was inserted into the center of a delineated inner section that was not inoculated. All puncture holes in the plastic packaging film were sealed using a glue gun immediately after inoculation and insertion of the probes. Each roast was placed in a separate Rival VSB2 Seal-a-Meal heat-resistant plastic bag (the Holmes Group Inc., Milford, Mass.) with the thermocouple probe extending out of the opening of the outer bag. A glue gun was used to seal the probe at the opening of the bag while allowing space at either side of the sealed probe for evacuating air from the roasts during vacuum packaging. All roasts were packaged under vacuum with a Multivac model A 300/51 vacuum packaging machine (Multivac Inc., Kansas City, Mo.). Each type$\mathrm{K}$ probe was attached to an Atkins model 37313 data recording digital thermometer (Atkins Technical Inc., Gainesville, Fla.) set to record temperature data at 10 -min intervals.

Heating and cooling. The turkey roasts were heated in a steamer at full steam to an internal temperature of $74^{\circ} \mathrm{C}$, according to 2001 FDA Food Code $(28,29)$. After reaching $74^{\circ} \mathrm{C}$, roasts were removed from the steamer and assigned to one of four cooling methods (CM1, CM2, CM3, and CM4) described in Table 1. In all treatments, each of four type-K probes (one for each cooling method) remained attached to a separate Atkins data recording thermometer to record cooling temperatures, until turkey roasts reached $5^{\circ} \mathrm{C}$. For treatment 1 , the heated roast was cut into four 9.9-cm sections using a sterile knife. Each section was spread apart, leaving a gap of approximately $6.85 \mathrm{~cm}$ between sections for cooling, and cooled uncovered in a walk-in refrigerator at $4{ }^{\circ} \mathrm{C}$. For treatment 2, the roast was loosely covered and cooled in a Servolift Eastern blast chiller, shock freezer model HCM51-20 (Servolift Eastern, Boston, Mass.). For treatment 3, the roast was loosely covered and refrigerated $\left(4^{\circ} \mathrm{C}\right)$. For treatment 4 , three heated roasts were placed next to one another on a sheet pan. The entire sheet pan with roasts was tightly covered with plastic then refrigerated. The middle roast was inoculated and fitted with a type-K probe.

Microbiological analysis. Viable populations of $C$. perfringens survivors in cooked turkey roasts were determined within 2 $\mathrm{h}$ after heating to $74^{\circ} \mathrm{C}$ and when roasts were cooled to $5^{\circ} \mathrm{C}$. Roasts were cut open using a sterile knife and the highly visible green cores of the roasts were aseptically excised. The excised 
FIGURE 1. Temperature profiles for cooling of cooked turkey roasts from 57 to $5{ }^{\circ} \mathrm{C}$ via application of four retail food service cooling methods (CM). Roast cut into quarters and held in walk-in refrigerator (CM1); whole roast loosely wrapped and held in blast chiller (CM2); whole roast loosely wrapped and held in walk-in refrigerator (CM3); whole roasts (three per bag) on sheet pans in walk-in refrigerator (CM4).

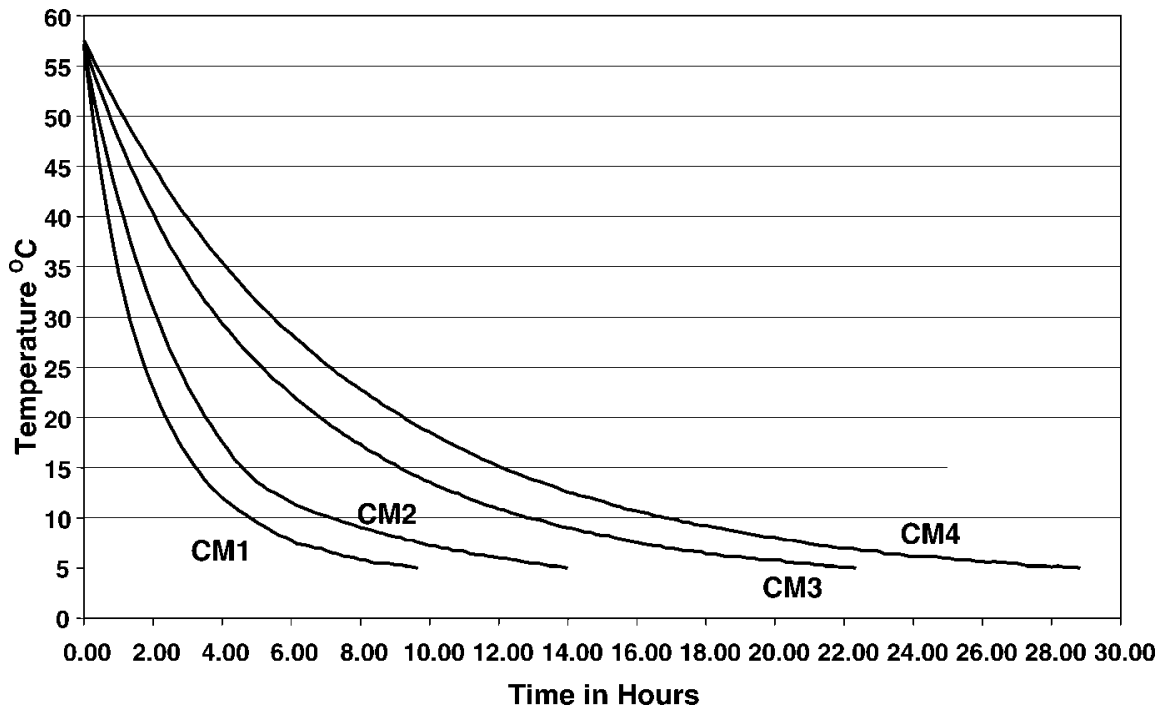

core samples were mixed with $100 \mathrm{ml}$ of sterile $0.1 \%$ peptone water in sterile stomacher bags (Fisher Scientific Co.) and pummeled at normal speed for $60 \mathrm{~s}$ using a Seward Stomacher 400 lab blender (Seward Ltd., Norfolk, UK). Tenfold serial dilutions of the meat homogenate were prepared in sterile $0.1 \%$ peptone water. Samples of meat homogenate or appropriate dilutions were pour-plated in duplicate using Shahidi-Ferguson perfringens agar base (Difco) with added filter-sterilized D-cycloserine (Sigma Chemical Company, St. Louis, Mo.) solution. All inoculated Shahidi-Ferguson perfringens D-cycloserine agar plates were incubated in anaerobic jars with Oxoid AnaeroGen AN35 sachet bags (Oxoid Ltd., Basingstoke, Hampshire, UK) at $37^{\circ} \mathrm{C}$ for $24 \mathrm{~h}$ before counting bacterial colonies. Black colonies were considered presumptive positive for $C$. perfringens. Randomly selected presumptive $C$. perfringens isolates from each sample were confirmed as gram-positive, nonmotile rods that reduced nitrate, fermented lactose, and liquefied gelatin in motility-nitrate and lactose gelatin media as described by Labbe (13).

Data analysis. Three independent replicate experiments were conducted, and results are reported as means. Cooling curves were developed from the downloaded Atkins 37313 recording thermometer data. Reported populations of viable $C$. perfringens in turkey roasts were determined by calculating the log value of bacterial counts on duplicate plates and the mean and standard deviation of three replicates using Microsoft Excel 2003 Software (Microsoft Inc., Redmond, Wash.) (15). Data from changes in viable counts resulting from the cooling methods were analyzed using the general linear models procedure of the Statistical Analysis System software program (SAS Institute Inc., Cary, N.C.)

TABLE 2. Mean time (hours) required for cooling turkey roasts from 57 to $21^{\circ} \mathrm{C}(\mathrm{I}), 21$ to $5^{\circ} \mathrm{C}\left(\right.$ II), and 57 to $5^{\circ} \mathrm{C}$ (III) using four retail food service cooling methods

\begin{tabular}{lcrr}
\hline \multirow{3}{*}{$\begin{array}{c}\text { Cooling } \\
\text { method }\end{array}$} & I & \multicolumn{3}{c}{ Cooling time (h) } \\
\cline { 2 - 4 } & & \multicolumn{1}{c}{ II } & \multicolumn{1}{c}{ III } \\
\hline CM1 & $2.27( \pm 0.10)^{a}$ & $6.33( \pm 0.86)$ & $8.60( \pm 0.92)$ \\
CM2 & $3.11( \pm 0.20)$ & $9.33( \pm 1.42)$ & $12.44( \pm 1.58)$ \\
CM3 & $6.22( \pm 0.35)$ & $13.80( \pm 2.40)$ & $20.02( \pm 3.08)$ \\
CM4 & $8.71( \pm 0.10)$ & $19.45( \pm 0.51)$ & $28.16( \pm 0.60)$ \\
\hline
\end{tabular}

${ }^{a}$ Mean ( \pm standard deviation) of three replicate experiments.
(16). Statistical analyses included analysis of variance and comparison of means by Tukey $(\alpha=0.05)$.

\section{RESULTS AND DISCUSSION}

Figure 1 shows the cooling curves (from 57 to $5^{\circ} \mathrm{C}$ ) for turkey roasts subjected to four retail food service cooling methods. The method of cooling that resulted in the fastest decrease in temperature of turkey roasts involved cutting the cooked roasts into quarters and refrigerating them uncovered at $4^{\circ} \mathrm{C}$ (CM1). Generally, the thickness or distance from the surface to geometric center of a food product is a major factor that affects the rate of heat loss. The smaller the distance the more rapid the heat loss. The cut sections of the quartered roasts had the smallest distance from the cut surface to the center $(4.95 \mathrm{~cm})$ compared with the thickness of whole roasts $(6.98 \mathrm{~cm})$. This effectiveness of reduced product thickness in facilitating heat loss is evident when the cooling time for refrigerated quartered roasts is compared with that for a whole roast in a blast chiller. An internal temperature of $21^{\circ} \mathrm{C}$ was achieved in 2.27 and $3.11 \mathrm{~h}$ for refrigerated quartered roast (CM1) and blastchilled whole roast (CM2), respectively (Table 2 ).

The problem of slow cooling is further exacerbated when whole roasts are held under refrigerator conditions. For example, refrigerated single whole roast (CM3) and refrigerated roasts (three per bag; CM4) cooled the slowest compared with all other methods evaluated. Times required for the internal temperature of roasts to cool from 57 to $21^{\circ} \mathrm{C}$ were 6.22 and $8.71 \mathrm{~h}$, respectively, for CM3 and CM4 (Table 2). Two factors that most likely contributed to the very slow heat loss from the three-bagged roasts subjected to CM4 are (i) the insulating effect of the two roasts that flanked the center roast (with probe), and (ii) the plastic bag that trapped heat around all three roasts. Roasts subjected to $\mathrm{CM} 3$ and $\mathrm{CM} 4$ also took the longest to cool from 21 to $5^{\circ} \mathrm{C}$. These results dramatically illustrate the heatinsulating effect of food cooled in bulk quantities.

Initial C. perfringens populations (4.23 log CFU per roast) decreased to $2.70 \log \mathrm{CFU}$ per roast in roasts analyzed within $2 \mathrm{~h}$ after heating to an internal temperature of 
TABLE 3. Changes in viable counts of $\mathrm{C}$. perfringens in turkey roasts based on differences between viable counts after cooling to $5^{\circ} \mathrm{C}$ and initial numbers in the raw product (4.23 log CFU per roast) or numbers in the cooked product (2.70 log CFU per roast) at $2 \mathrm{~h}$ after heating to $74^{\circ} \mathrm{C}$

\begin{tabular}{cccc}
\hline $\begin{array}{c}\text { Cooling } \\
\text { method }\end{array}$ & $\begin{array}{c}\text { Viable count } \\
\text { after cooling } \\
\text { to } 5^{\circ} \mathrm{C}\end{array}$ & $\begin{array}{c}\text { Log change } \\
\text { in viable count }^{a}\end{array}$ & $\begin{array}{c}\text { Log change } \\
\text { in viable count }\end{array}$ \\
\hline $\mathrm{CM} 1$ & $2.78( \pm 0.26)^{c}$ & $-1.45( \pm 0.10) \mathrm{A}$ & $0.08( \pm 0.26) \mathrm{A}$ \\
$\mathrm{CM} 2$ & $3.37( \pm 0.15)$ & $-0.86( \pm 0.17) \mathrm{A}$ & $0.67( \pm 0.15) \mathrm{A}$ \\
$\mathrm{CM} 3$ & $5.73( \pm 0.12)$ & $1.50( \pm 0.70) \mathrm{B}$ & $3.03( \pm 0.12) \mathrm{B}$ \\
$\mathrm{CM} 4$ & $8.23( \pm 0.36)$ & $4.00( \pm 0.61) \mathrm{C}$ & $5.53( \pm 0.36) \mathrm{C}$ \\
\hline
\end{tabular}

${ }^{a}$ Viable counts in roasts $\left(5^{\circ} \mathrm{C}\right)$ minus initial viable numbers in raw product.

${ }^{b}$ Viable counts in roasts $\left(5^{\circ} \mathrm{C}\right)$ minus numbers of survivors at 2 h after heating to $74^{\circ} \mathrm{C}$.

Mean ( \pm standard deviation) of three replicate experiments. Mean values with different letters in the same column are significantly different $(P<0.05)$.

$74^{\circ} \mathrm{C}$. Taormina and Dorsa (22) suggested that heating can alter the levels of $C$. perfringens spores and vegetative cells in heated foods entering the cooling process. Shigehisa et al. (17) demonstrated that heating $C$. perfringens $\mathrm{H}-3$ spores from 20 to $60^{\circ} \mathrm{C}$ in fluid thioglycollate medium at rates of 25,20 , and $13^{\circ} \mathrm{C} / \mathrm{h}(1.6-, 2-$, and 3 -h heating time, respectively) resulted in reduction of initial spore populations. Those same authors reported an increase in total counts (vegetative cells and spores) of $C$. perfringens before death of vegetative cells occurred above $50^{\circ} \mathrm{C}$. Also, there was a 2-log decrease in initial numbers of spores following heating from 20 to $60^{\circ} \mathrm{C}$ for $5.7 \mathrm{~h}$ (heating rate of $7^{\circ} \mathrm{C} / \mathrm{h}$ ). In the present study the turkey roasts took $3 \mathrm{~h}$ for their internal temperature to increase from 4 to $74^{\circ} \mathrm{C}$ (heating rate $23^{\circ} \mathrm{C}$ / h) (data not shown). The observed change in viable population of $C$. perfringens in cooked roasts entering the cooling process represented a $1.45-\log$ reduction in the initial viable spore count. It is likely that germination and outgrowth of some spores occurred during relatively slow heating of the turkey roasts. Spores that germinated and produced vegetative cells would have become more susceptible to heat as the temperature became lethal, leaving only those spores that had not yet germinated to enter the cooling process.

Table 3 shows changes in viable counts of $C$. perfringens in turkey roasts based on differences between viable counts after cooling to $5^{\circ} \mathrm{C}$ and initial numbers in the raw product (4.23 log CFU per roast) or numbers in the cooked product (2.70 $\log \mathrm{CFU}$ per roast) at $2 \mathrm{~h}$ after heating to $74^{\circ} \mathrm{C}$, in reference to the time that each method took to reduce the internal temperature of the roasts from 57 to $5^{\circ} \mathrm{C}$. No increase in initial viable counts was observed in roasts cooled using CM1 or CM2. In fact, roasts cooled by both of these methods exhibited varying decreases in initial viable counts of the pathogen (Table 3). The refrigerated whole roast (CM3) and whole roasts (three per bag) (CM4) exhibited a 1.50- and 4.00-log increase in viable counts, respectively. Both of these cooling methods took the lon- gest to reduce the internal temperature of the roasts from 57 to $21^{\circ} \mathrm{C}$ (Table 2), thus allowing enough time (6.22 and $8.71 \mathrm{~h}$ ) for proliferation of $C$. perfringens at temperatures that are conducive to rapid growth of the pathogen. $C$. perfringens is mesophilic and grows rapidly between 37 and $45^{\circ} \mathrm{C}(6)$, with 20 and $50^{\circ} \mathrm{C}$ representing lower and upper growth temperature limits, respectively (7). Under optimal conditions $C$. perfringens exhibits a generation time as short as $7 \mathrm{~min}$ (7). Therefore, it was not surprising that both of these cooling methods resulted in relatively large increases in initial populations of $C$. perfringens.

When the number of $C$. perfringens survivors in roasts (at $2 \mathrm{~h}$ after heating to $74^{\circ} \mathrm{C}$ ) was used to determine changes in viable counts during cooling, larger increases in populations of the pathogen were realized (Table 3). All cooling methods resulted in increases in numbers of the pathogen; however, these increases from CM1 and CM2 (0.08 and $0.67 \log$ CFU per roast, respectively) were not significantly different $(P>0.05)$. In contrast, CM3 and CM4 resulted in $\log$ increases of 3.03 and 5.53, respectively $(P<0.05)$. These increases in viable counts of $C$. perfringens resulting from use of CM3 and CM4 far exceed the USDA Food Safety and Inspection Service safe cooling standard criteria (23). The criteria allow no more than a 1.0-log increase between 48.9 and $12.8^{\circ} \mathrm{C}$ within $6 \mathrm{~h}$ and represent compliance guidelines to control growth of $C$. perfringens to dangerous levels in cooked meat and poultry products. While the refrigeration of three roasts together in a bag (CM4) is not a commonly used cooling method, it has been observed in practice and serves as a worst-case scenario for comparison purposes.

Our findings are consistent with those of previous studies on the growth of $C$. perfringens in cooked turkey meat during cooling. Kalinowsky et al. (11) demonstrated that cooling uncured cooked turkey from 48.9 to $12.8^{\circ} \mathrm{C}$ for 6 $\mathrm{h}$ resulted in less than $1.0-\log (0.83-\log )$ increase in growth of $C$. perfringens. For that same critical temperature range, Steele and Wright (21) reported that $8.9 \mathrm{~h}$ of cooling was the maximum time necessary to prevent a $1.0-\log$ increase in $C$. perfringens in uncured cooked turkey roasts. Data from cooling profiles generated in the present study indicated that CM1, CM2, CM3, and CM4 took 3.7, 5.6, 10.4, and $14.0 \mathrm{~h}$, respectively, to reduce the internal temperature of turkey roasts from 48.9 to $12.8^{\circ} \mathrm{C}$. CM1 and $\mathrm{CM} 2$ were the only two cooling methods that reduced the internal temperature of the roasts from 48.9 to $12.8^{\circ} \mathrm{C}$ in less than 6 or $8.9 \mathrm{~h}$ and restricted growth of the pathogen to less than 1.0 $\log$ (Table 3).

The USDA Pathogen Modeling Program (PMP) version 7.0 for estimating $C$. perfringens growth at changing temperatures during cooling of cooked meats was used to predict the growth of the pathogen in cooked turkey roasts cooled via the four different cooling methods used in the present study. The model predicted that cooling cooked meats from 48.9 to $12.8^{\circ} \mathrm{C}$ in 3.7 (CM1), 5.6 (CM2), 10.4 (CM3), and $14.0 \mathrm{~h}$ (CM4) would result in relative log growth of $0.10,0.23,1.68$, and 3.39, respectively. Based on data from the present study, cooling turkey roasts using CM1, CM2, CM3, and CM4 resulted in 0.08-, 0.67-, 3.03-, 
and 5.53-log growth of the pathogen, respectively. Predictions from the PMP and the results of the present study both suggest that CM1 and CM2 would restrict growth of the pathogen to less than $1.0 \log$, whereas CM3 and CM4 would allow growth of the pathogen by more than $1 \mathrm{log}$. For two of the cooling methods (CM3 and CM4), the PMP markedly underpredicted the extent of growth of $C$. perfringens in the turkey roasts. These results may be attributed to faster than predicted growth of $C$. perfringens (strain ATCC 10388) in cooked turkey roast during cooling. The actual model (10) that formed the basis of the PMP to predict growth of $C$. perfringens at changing temperatures during cooling of cooked meat products was used in a validation study recently conducted by Smith and Schaffner (19). Those researchers demonstrated that the model consistently underpredicted increases in growth of the pathogen when exponential cooling occurred at two different rates in the cooling process. On comparing their experimental data with the PMP predicted values from single cooling rate studies, the researchers suggested that the model could be improved for describing the growth of $C$. perfringens during exponential cooling.

The four cooling methods for turkey roasts evaluated in the present study represent practices observed in school food service operations (5). None of the cooling methods achieved the amended 2001 Food Code recommendations for cooling potentially hazardous foods from 57 to $21^{\circ} \mathrm{C}$ in $2 \mathrm{~h}$ and from 21 to $5^{\circ} \mathrm{C}$ in an additional $4 \mathrm{~h} \mathrm{(29).} \mathrm{However,}$ CM1 and CM2 met the USDA stabilization performance standard (25) in that less than 1.0-log increase in growth of $C$. perfringens was achieved using these two cooling methods. In contrast, CM3 and CM4 failed to meet this standard. The walk-in refrigerator used in the present study was not the forced-air type of cooling system and therefore simulated the refrigeration conditions commonly observed in school food service establishments. Turkey roasts were cooled uncovered or loosely covered (except for CM4) with the doors of the cooling equipment closed during the entire cooling process. These practices represent a conservative scenario for the cooling of foods and do not account for variables in actual food service establishments that could potentially increase cooling time. Examples of such variables include frequent opening and closing of a refrigerator door and wrapping hot food tightly with aluminum foil or film before cooling.

This study simulated actual food service cooling methods observed in school food service operations. Measurements of time, temperature, and growth of $C$. perfringens during cooling of turkey roasts provided data that were compared with cooling recommendation of the amended 2001 FDA Food Code standards and USDA Food Safety and Inspection Service safe cooling standard criteria for cooked meat and poultry products. Significant findings of the study indicated that time standards were not met, and typical cooling methods, based on measurements of cooling time and temperature, are unacceptable. The most significant finding of the study was that two cooling methods (CM3 and CM4) caused an increase in $C$. perfringens populations, enough to cause foodborne illness. Results of the present study indicate that normal refrigeration methods typically used in school food service operations are unacceptable for cooling whole turkey roasts to ensure the microbiological safety of these meat products. If food service operations are unable to invest in a blast chiller then it is imperative that whole cooked turkey roasts be cut into quarters prior to refrigeration $\left(4^{\circ} \mathrm{C}\right)$ to facilitate rapid cooling. The data generated in the present study are useful for educating food service professionals about the microbial safety of cooling methods for potentially hazardous foods. This approach may prove effective in curtailing the practice of potentially dangerous cooling methods in food service operations to avoid outbreaks of foodborne disease caused by C. perfringens.

\section{ACKNOWLEDGMENTS}

The authors gratefully acknowledge the in-kind support for this project from the USDA and the National Aeronautics and Space Administration Food Technology Commercial Space Center. Atkins 37313 data recording thermometers were generously provided by Dr. Sam Beattie, Food Safety Extension Specialist at Iowa State University.

\section{REFERENCES}

1. Adams, D. M. 1973. Inactivation of Clostridium perfringens Type A spores at ultra-high temperatures. Appl. Microbiol. 26:282-287.

2. Bryan, F. L. 1988. Risks of practices, procedures, and processes that lead to outbreaks of foodborne diseases. J. Food Prot. 51:663-673.

3. Centers for Disease Control and Prevention. 2000. Surveillance for foodborne disease outbreaks-United States, 1993-1997. Morb. Mortal. Wkly. Rep. CDC Surveillance Summaries 49:1-62.

4. Duncan, C. L., and D. H. Strong. 1968. Improved medium for sporulation of Clostridium perfringens. Appl. Microbiol. 16:82-89.

5. Henroid, D., and J. Sneed. 2004. Readiness to implement hazard analysis critical control point (HACCP) systems in Iowa schools. $J$. Am. Diet. Assoc. 104:180-185.

6. Heredia, N. L., and R. G. Labbe. 2001. Clostridium perfringens, p. 133-141. In R. G. Labbe and S. Garcia (ed.), Guide to foodborne pathogens. John Wiley \& Sons, Inc., New York.

7. Jay, J. M. 2000. Food poisoning caused by gram-positive sporeforming bacteria, p. 461-484. In Modern food microbiology. Van Nostrand, New York.

8. Johnson, E. A. 1990. Clostridium perfringens food poisoning, p. 229-240. In D. O. Cliver (ed.), Foodborne diseases. Academic Press, Inc., San Diego.

9. Juneja, V. K., J. E. Call, and A. J. Miller 1993. Evaluation of methylxanthines and related compounds to enhance Clostridium perfringens sporulation using a modified Duncan and Strong medium. $\underline{J}$. Rapid Methods Autom. Microbiol. 2:203-218.

10. Juneja, V. K., R. C. Whiting, H. M. Marks, and O. P. Snyder. 1999. Predictive model for growth of Clostridium perfringens at temperatures applicable to cooling of cooked meats. Food Microbiol. 16: 335-349.

11. Kalinowsky, R. M., R. B. Tompkin, P. W. Bodnaruk, and W. P. Pruett. 2003. Impact of cooking, cooling, and subsequent refrigeration on the growth or survival of Clostridium perfringens in cooked meat and poultry products. J. Food Prot. 66:1227-1232.

12. Labbe, R. 1989. Clostridium perfringens, p. 191-234. In M. P. Doyle (ed.), Foodborne bacterial pathogens. Marcel Dekker, Inc., New York.

13. Labbe, R. G. 2001. Clostridium perfringens, p. 325-330. In F. P. Downes and K. Ito (ed.), Compendium of methods for the microbiological examination of foods. American Public Health Association, Washington, D.C.

14. Mead, P. S. 1999. Food-related illness and death in the United States. Emerg. Infect. Dis. 5:607-625.

15. Microsoft Excel. 2003. Microsoft Corporation, Redmond, Wash. 
16. SAS Institute. 1995. SAS/STAT user's guide. SAS Institute, Inc., Cary, N.C.

17. Shigehisa, T., T. Nakagami, and S. Taji. 1985. Influence of heating and cooling rates on spore germination and growth of Clostridium perfringens in media and in roast beef. Jpn. J. Vet. Sci. 47:259-267.

18. Smith, A. M., D. A. Evans, and B. M. Buck. 1981. Growth and survival of Clostridium perfringens in rare beef prepared in a water bath. J. Food Prot. 44:9-14.

19. Smith, S., and D. W. Schaffner. 2004. Evaluation of a predictive model for Clostridium perfringens growth during cooling. J. Food Prot. 67:1133-1137.

20. Snyder, O. P., and J. A. Labalestra. 2004. Comparison of the bimetallic coil thermometer and thermocouple for validating food cooling. Food Prot. Trends 24:423-428.

21. Steele, F. M., and K. H. Wright. 2001. Cooling rate effect on outgrowth of Clostridium perfringens in cooked, ready-to-eat turkey breast roasts. Poult. Sci. 80:813-816.

22. Taormina, P. J., and W. J. Dorsa. 2004. Growth potential of Clostridium perfringens during cooling of cooked meats. J. Food Prot. 67:1537-1547.

23. U.S. Department of Agriculture. 1999. Performance standards for the production of certain meat and poultry products. 9 CFR 301, 317, 318, 320, 381. Office of Federal Register, National Archives and Records Administration, Washington, D.C.

24. U.S. Department of Agriculture, Food Safety and Inspection Service.
1999. Compliance Guidelines for cooling heat-treated meat and poultry products (stabilization). Food Safety and Inspection Service, U.S. Department of Agriculture. Available at: www.fsis.usda.gov. Accessed 15 May 2004.

25. U.S. Department of Agriculture, Food Safety and Inspection Service. 1999. Performance standards for the production of certain meat and poultry products: final rule. Fed. Regist. 64:732-749.

26. U.S. Department of Agriculture, Food Safety and Inspection Service. 2001. Performance standards for the production of meat and poultry products. Fed. Regist. 66:12589-12636.

27. U.S. Food and Drug Administration. 2000. Report of the FDA retail food program database of foodborne illness risk factors. Available at: http://vm.cfsan.fda.gov/ acrobat/retrsk.pdf. Accessed 16 March 2004.

28. U.S. Food and Drug Administration, Center for Food Safety and Applied Nutrition, FDA 2001 Food Code. 2001. Destruction of organisms-raw animal foods. 2001 Food Code. In U.S. Department of Health and Human Services Public Health Service FDA 2001 Food Code (Chap. 3). Available at: http://www.cfsan.fda.gov/ dms/ fc01-3.html. Accessed 7 June 2004.

29. U.S. Food and Drug Administration, Center for Food Safety and Applied Nutrition, FDA Supplement to the 2001 Food Code 2003. Food amendments, additions, and deletions. In U. S. Department of Health and Human Services Public Health Service FDA Supplement to the 2001 Food Code (chap. 3). Available at: http://www.cfsan. fda.gov/ dms/fc01-sup.html\#p1. Accessed 29 May 2004. 